\title{
Legal Terminology. Some Aspects for a New Methodology
}

As Jan Engberg wrote in his description of the workshop the most important aspect in the legal LSP research is taking account of the overall communication process, which means taking account of the framework of legal systems and in particular the boundaries and restrictions of national legal systems.

My presentation will deal with the methodology of a systematic terminological analysis of legal concepts and a new type of comparative approach to multilingual terminography where more than one legal system is involved.

Legal dictionaries have been the subject of much criticism, essentially because they offer too little information on the terms and the concepts. Traditionally, legal dictionaries on the market are the product of a lexicographical approach to legal terminology listing different meanings of one word and proposing possible equivalents in the other language. Users of such dictionaries - too often not familiar with the legal system of the target language - wonder which of the given equivalents they can use in their specific (translational) situation and search the dictionary entry for possible hints or pieces of information which in most cases they do not find.

A thorough change is necessary which touches the following three aspects:

methodology of research,

representation of results, and as well

user attitude towards terminographical products.

* Peter Sandrini

Leopold-Franzens-Universität Innsbruck

Inst. für Übersetzer und Dolmetscherausb.

Fischnalerstr. 4

A-6020 Innsbruck 
Let us begin with the last aspect by which we understand the way dictionaries, glossaries or terminology databases and, in particular, proposed equivalents are looked upon and made use of.

\section{User attitude}

The average user tends to take one of the equivalents for his textual task and attributes the responsibility to the dictionary. This is the wrong attitude in so far as two types of equivalence could be distinguished clearly: the first is conceptual equivalence which means that two legal concepts are identical with respect to all their conceptual features as well as their conceptual extension. This particular case of absolute or total equivalence, as we will show further down in this paper, is possible only if both concepts refer to the same legal system. In cases where the two concepts come from different legal systems absolute equivalence is no longer possible. A blurred concept of more or less, of partial, relative or near equivalence takes its place the criteria for which are hard to define.

The second type of equivalence is the concept of text based equivalence. It states that two concepts can be regarded as equivalents in two texts with a particular background, i.e. a defined class of addressees and a defined scope and purpose of the target text. This type of equivalence is not absolute, it is situational and depends on the purpose or on the legal environment of the translation. Since absolute equivalence is not possible with concepts coming from different legal systems, dictionaries can propose equivalents that could be used in some cases but would lead to inconsistencies or mistranslations in others. In the course of the production of a dictionary entry lexicographers hardly can foresee and take account of all possible translation situations, this is virtually impossible. So users cannot expect from a legal dictionary to give an "immediately insertable equivalent ... it is the task of the translator not to hunt for the insertable item, but to use the given information as an aid in his all-important decision-process in recreating the text." (SnellHornby 1990: 224)

Much of the responsibility for the textual equivalent rests with the translator who is the only one able to judge the particular communicative situation, to assess the role of the target text and the overall aim of his translation effort. What he can expect and what he must demand 
from legal dictionaries, glossaries or terminology databases is information on the terms and concepts on the basis of which he can make his text-dependent decisions: the better the information provided the more well-founded will be his choices. Legal dictionaries have to be regarded as a tool supporting the intellectual decision-making process of the translator.

The main task of a terminographical product is to supply the user with as much information as possible. The type of information needed depends on the decisions to be taken and on the communicative situation of both source and target text. In legal translation the overall mostimportant factor are the legal systems involved both with regard to the source text as well as to the target text (Madsen 1997, Kjaer 1995). This is why the information needed must relate to the legal content of each concept in the particular legal system. The best would be to write legal dictionaries not for languages, e.g. english - french, but for legal systems, i.e. UK-legal terminology versus legal terminology used in France. As this option is very limited and economically not really viable, language oriented legal dictionaries must at least indicate the legal system in which the given terms are used. This is especially important for languages used in more than one legal system: e.g. an entry with an English term on one side and two or more German terms on the other is more or less useless; on the English side the terms have to be documented whether they come from the US, Australia, Ireland or from the UK legal system, on the German side the same is true for the German, Austrian or Swiss legal system.

The national legal system has to be regarded as a framework for all legal communication and it affects not just the languages but obviously also terminology and the content and formal structure of texts as well.

\section{Nature of legal concepts}

Legal terminology is rooted in national legal systems and before we can go into a methodology for terminographical work within the legal domain the very nature of legal concepts and their intrinsic pecularities have to be shown. We also regard the legal content, that is the conceptual meaning of terms as the overall criterion for a comparative analysis: consequently we speak of legal concepts and disregard, for the moment, the term or the linguistic representation of concepts. 
Legal concepts are formed by abstraction of the general features from a large number of instances. Thus "contract" is the legal concept abstracted from various instances of legal relationships which are called contracts. Usually after a long discussion by the general public, politicians, law consultants, legislative bodies, etc., a group of actual or possible situations in real life which shall be the object of legislation is described with the aim of regulating the interaction of humans (civil law) or of controlling people's behaviour (penal law). Most legal concepts originate from such a process, e.g. abortion, dismissal, leasing, factoring, murder, theft, etc.

Rooted in a national legal system, concepts are subject to the moral values predominant in this particular society at a particular period in time. Furthermore, every rule, every law is the result of a political discussion and decision process: a society deliberately chooses the basis on which its members will live together. It is in the interest of lawmakers to make provisions so that rules will be obeyed, thereby serving their purpose. This would make lawmakers aim at most accurate definitions to guarantee that this particular situation will always be managed the way they have decided. Nevertheless, they cannot foresee how society with its moral values will evolve or whether the "real life situation" at the basis of the rule will change completely in time.

Legal concepts basically:

1) originate from a system of moral values

2) refer to specific "real life situations" within a particular society

3) contain provisions on how to handle these situations

Culture-specific criteria play a significant role both in the process of coining legal concepts and in the process of applying them. In the course of the administration of justice, concepts have to be applied to single concrete cases. Precise intensional definitions in written law would hinder the adaptation of the abstract rule to the single case in question. The more characteristics for the legal validity of a concept there are in a law, the fewer possibilities judges have for an extensional application.

Definitions of legal concepts should leave room for interpretation of laws and the adaptation of rules to new or changed social and moral environments. For a fair and just application of laws and equal treatment of citizens, judges must have a certain range of freedom in apply- 
ing abstract rules to concrete cases which can differ considerably. On the other hand, if this freedom becomes too far-flung there will be insecurity about the application of laws and citizens will not know what to expect from the administration of justice.

Furthermore the extensional definition of a legal concept can change considerably by application of the analogy principle, i.e. extending the applicability of a rule to other cases not provided for in the law. Legal concepts can therefore not be described adequately by intensional or extensional definitions. The process of the application of law and of the concepts requires texts to be interpreted - a task for which each legal system has evolved its own rules of interpretation and application causing legal concepts to be redefined by judges, lawmakers or scholars.

All this aspects contribute to the fact that legal concepts are subject to a certain degree of vagueness and, hence, legal definitions are open definitions.

\section{Methodology}

On the basis of what has been said we must assume that legal terms from different legal systems cannot be equivalents, unless it is a consequence of complete identity of moral values, legal provisions, interpretation rules and forms of application of laws - but this again would mean the same legal framework.

Legal terminography cannot be reduced to a search for identical concepts in two or more legal systems, simply because this would lead to a fruitless debate about when and where conceptual equivalence is possible. A new methodology is necessary which focusses on the cases of partial or relative equivalence of overlapping characteristics. To achieve this we have to abandon the concept of equivalence in favour of a more flexible comparative approach. The difference lies in the presupposition that legal concepts as part of a national system of laws are fundamentally different across legal systems and that only a comparative approach is possible; the establishing of equivalence relations is not.

What has to be done primarily is to document and describe legal concepts within their natural environment. This implies two consequences: first, concepts should not be treated as isolated items but as parts of a system constructed on relations between its components, and second, 
that the information provided is always based on the national legal system which the concept belongs to.

The description of legal concepts starts from a single concept but takes account of all the relations this particular concept has with its surrounding concepts, i.e. with all concepts that contribute to create a special legal setting intended to regulate or provide the legal basis for a particular aspect of real life.

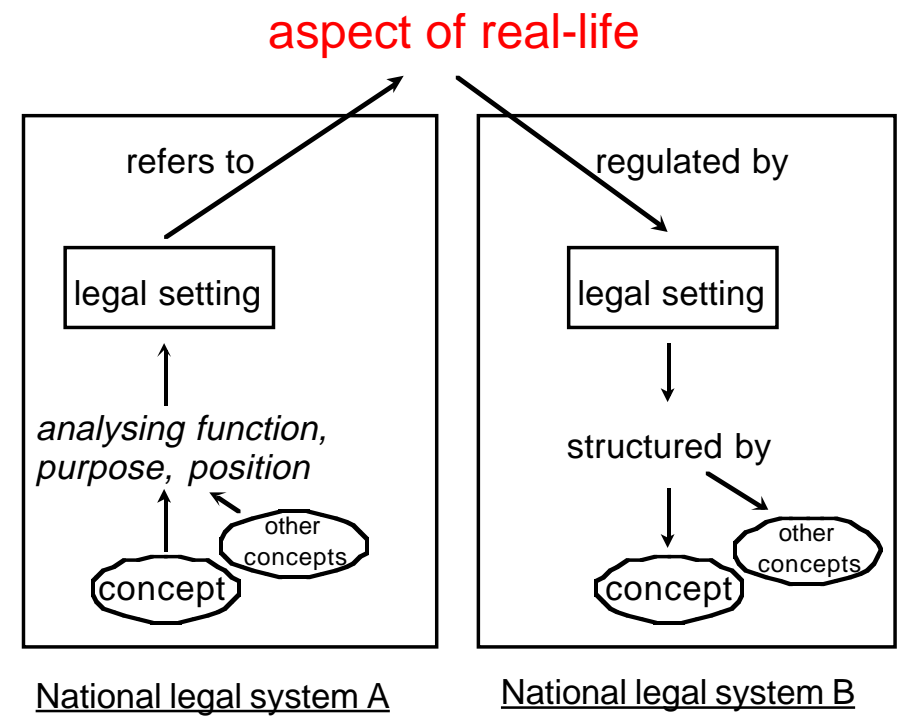

Let us take for example the term licenziamento in Italian: it is no use to search for a German equivalent in Austrian Law, if you do not comprehend the terms licenziamento per giusta causa and licenziamento per giustificato motivo, or take into account the distinction from the side of the persons involved licenziamento da parte del datore di lavoro and licenziamento da parte del lavoratore. The German term Kündigung is to some extent comparable to licenziamento per giustificato motivo, whereas licenziamento per giusta causa compares to the German Entlassung. Austrian Labour Law makes a strict distinction between the dismissal of a worker to a certain degree on the basis of hire and fire (Kündigung) with limited applicability, and a dismissal caused mainly by serious reasons in the conduct of the worker (Entlassung). Italian 
Law makes the same distinction but has a common hyperonym (licenziamento) which is not there in German. So the environment of legal concepts must be considered and all concepts from the same concept system must be documented.

Such a methodology of terminographical work comprises all steps from the single concept to a group of concepts related to each other, to a legal setting and finally to a particular aspect of real life, the object of regulatory efforts which is the only possible neutral bridge to another legal system. The aspect of real life which is regulated by statutes and laws constitutes at the same time the starting point for terminographical work: since it is independent of national legal systems - as a piece of reality it is outside the Law - this is the only common factor in a comparative analysis of terminology from different legal systems where we can speak of absolute identity or equivalence. Each legal system makes an independent regulatory effort which is influenced heavily by cultural and sociological factors and develops a specific legal solution. The legal setting - understood as the totality of laws, regulations, customs for this particular situation - represents a structured whole where legal concepts are small building blocks with a specific function and purpose. It is the task of terminographical work to describe the concepts on the basis of their specific function within the overall legal setting.

Once we have a thorough description of concepts, their function and purpose, and their relationship to the other concepts which are part of the same legal setting within one national legal system, the process of comparison may start. We compare legal concepts as parts of a larger conceptual system, and in many cases a link will be established not between single concepts but between concept groups.

\section{Comparativ approach}

comparison of independent concept

aim: establishing links between

concept groups

\begin{tabular}{|c|c|}
\hline Legal concepts & compared on the basis of \\
\hline 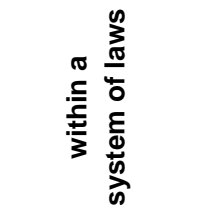 & $\begin{array}{l}\text { function } \\
\text { position } \\
\text { legal setting }\end{array}$ \\
\hline
\end{tabular}


The basis for comparison is the function of each concept within the legal setting expressed by a functional definition which describes the role of the concept with regard to the overall regulatory intention of the whole legal setting. Further clues for comparison can be the position of the concept within the conceptual system and the legal setting itself, i.e. you cannot compare concepts from different legal environments, that means both legal settings (source legal system and target legal system) must refer to the same aspect of real life.

\section{Representation of results}

Such a comparative approach is not intended to lead to one-to-one equivalents in a dictionary or glossary. Its main goal is to convey information on the concepts within each legal system and to offer some kind of bridges between the two legal systems in order to lead the user from one concept in one legal system to comparable concepts in the other legal system. That is, the user should get an answer to this question: how and with the help of which specific concepts is the legal setting for the same aspect of life constructed in the target legal system.

The aim is to give a thorough insight into the use of terms and concepts in the target legal system for a comparable legal solution to the same real life problem. Once the user - lawyer, translator, writer or whatever - knows what terms and what concepts the reader from the target legal system is familiar with, he is able to take textual decisions based on the particular circumstances of the case. The product of such a comparative terminological approach provides the necessary information, but the translator has to take the actual decisions as to what terms he can or cannot use in the target text to avoid misunderstandings or for which concepts he should give an additional explanation, and so on. These decisions are based on textual equivalence the criteria of which are part of an overall translation strategy.

The result of this comparative analysis can not be managed in simple two-sided dictionary entries. The first task of legal terminography is to document the concepts in each legal system. Only then functional bridges can be set up between the two distinct systems. These bridges or links do not express cases of equivalence but represent a chance for the user to have a look into a comparable setting within the other legal system. A new entry model must be developped which takes account of 
all possible relations between legal systems and their respective concepts. In a first attempt to classify the relations between concepts and concept groups from one legal system and those from another legal system the following links for a new model for a terminology database are proposed (Sandrini 1996: 242). The first group of possible links to the other legal system are between single concepts:

Direct relation: this links to a concept in the other legal system which has the same intension i.e. identy of conceptual features. In contrast to absolute equivalence there could well be differences regarding the extension of the concept.

Functional relation: the two concepts have the same function as an element in the legal setting of each legal system and as such they have some conceptual features in common.

Indirect relation: both concepts relate to a comparable function within the legal setting of each legal system, but they have no features in common.

The second group represents links between a group of concepts from the source legal system and a group of concepts from the target legal system. These are additional to the first group and can be regarded as more general links between the two legal systems:

Concept structure: if concept relations are taken account of in the course of terminographical work they could represent an aid for the user to see if the superordinate concept or any other related concept links to concepts in the other legal system.

Legal setting: the reference to the whole legal setting constitutes the only possible criterion for equivalence between two distinct legal systems in so far as in both systems we have a legal solution for the same aspect of real life, and the set of concepts used for this purpose in each system can be regarded as having the same function. So the user should have the possibility of seeing all the concepts which contribute to this particular legal setting in the other legal system.

Classification: a subject field classification combines legal settings for particular problems to broader categories which the user can browse. The all-important purpose of such a terminology database would be to convey as much information as possible on the concepts and the terms used in both legal systems. The final product resembles - more than a dictionary - a knowledge base on a very specific legal subject which 
shows a net of relevant concepts in one legal system with the possibility of changing into another net of legal concepts belonging to a second national legal system.

\section{Conclusions and outlook}

Descriptive multilingual terminography involving two or more legal systems should not take decision concerning the choice of terms as it would be the case with normative terminology or translation studies. A descriptive approach should limit itself to provide insight into the way concepts and terms are used in their respective legal environments. It should provide information but should not seek artificial on-to-one equivalences. Information on a concept is obtained via definitions and contexts but also via legal sources in which the concept plays a central role.

We should like to stress that legal terminography must concentrate on the elements of a legal solution to a real life problem. However, any terminographic study should cover more than one legal solution for a larger subject field. Where focus is on one particular legal setting, it is important to come up with a set of coherent concepts and not isolated items. It would be easy to combine the terminology of more than one such legal setting or of connected settings and fit them into a larger terminographical product.

Terminological activities should cover small and very specific subject fields in order to achieve high quality. It would for example be difficult to make a terminographic study on Criminal Law or Labour Law; studies should rather start from special branches of these disciplines such as for example the protection against dismissal or immigration offenses etc. In a second step these studies could be expanded to include other specific topics. These small glossaries could then be combined into larger collections which cover a broader subject field such as Criminal Law. Still, it is absolutely necessary to keep alive the systematic aspect of concepts contributing to the same objective.

The focus on a common denominator between two independent national legal systems, that is on a particular aspect of life as the object or regulatory efforts, could very well also be a starting point for the analysis and the confrontation of text types from different legal systems. As in terminology the analysis should first of all identify a communi- 
cative situation independently of legal systems. Then the legal setting for this particular communicative context - statutes, laws, regulations, etc. - could be analysed leading to the individual communication acts and text types for each legal system. Text types must be regarded as specific to a national legal system until a comparative analysis proves the existence of corresponding textual features and text types in both legal systems in which case an abstract text type may be defined.

\section{Literatur}

Kjær, Anne Lise (1995). Vergleich von Unvergleichbarem. Zur kontrastiven Analyse unbestimmter Rechtsbegriffe. In Kromann, HP.; Kjaer, A. (Hg). Von der Allgegenwart der Lexikologie. Kontrastive Lexikologie als Vorstufe zur zweisprachigen Lexikographie. Kopenhagen.

Madsen, Dorte (1997). Towards a Description of Communication in the Legal Universe. Translation of legal Texts and the Skopos Theory. Fachsprache, Bd.Nr. 1/1997. 17-27.

Sandrini, Peter (1996). Comparative Analysis of Legal Terms: Equivalence Revisited. In Galinski, Ch.; Schmitz, K.-D. (Hg). TKE '96. Frankfurt: Indeks, 342-351.

Sandrini, Peter (1996). Der Rechtsbegriff: Implikationen für die mehrsprachige Terminologiearbeit. In Budin, Gerhard (Hg.). Multilingualism in Specialist Communication. Bd.Nr. 2. Wien: TermNet. 1105-1123.

Sandrini, Peter (1996). Terminologiearbeit im Recht. Deskriptiver begriffsorientierter Ansatz vom Standpunkt des Übersetzers. Wien: TermNet.

Snell-Hornby, Mary (1990). Dynamics in meaning as a problem for bilingual lexicography. In Tomaszczyk, Jerzy; Lewandowska-Tomaszczyk, Barbara (Hg). Meaning and Lexicography. Linguistic \& Literary Studies in Eastern Europe (LLSEE). Amsterdam/Philadelphia: John Benjamins. 
